\title{
Extramedullary plasmacytomas in the head and neck region
}

\author{
Jos Straetmans • Robert Stokroos
}

Received: 16 September 2007 / Accepted: 8 February 2008 / Published online: 26 February 2008

(c) The Author(s) 2008

\begin{abstract}
Extramedullary plasmacytoma (EMP) arises outside the bone marrow, particularly in the head and neck region (nasopharynx, nose cavity, sinuses, and tonsils), and can be associated with multiple myeloma (MM). Three cases of EMP in the head and neck region are described: a first case describes an EMP of the subglottis 3 years after treatment of MM, a second case of an EMP solitary in the middle ear presenting as a jugular foramen syndrome, and a third case of an EMP localised at the epiglottis, recurring at the floor of the nose cavity. Treatment of each EMP was surgical. We reviewed literature about aetiology, clinical course, diagnostics, treatment and prognosis. Important presenting symptoms vary from epistaxis, rhinorrhoea, a sore throat, dysphonia to haemoptoea. Association with MM must be confirmed or excluded. Histopathological examination, with immunological staining or flow cytometry confirms the diagnosis. CT and MRI are useful in staging EMP. The treatment of EMP is surgery and/or radiotherapy. The prognosis depends on tumour size $(>5 \mathrm{~cm})$ and nodal involvement. The 10 -year survival rate is $50-80 \%$.
\end{abstract}

Keywords Extramedullary plasmacytoma . Jugular foramen · Subglottic · Nasal cavity ·

Treatment $\cdot$ Prognosis $\cdot$ Incidence

\section{Introduction}

Plasmacell disorders are characterised by the accumulation of monoclonal plasmacells that all produce the same

J. Straetmans $(\bowtie) \cdot$ R. Stokroos

Department of Otorhinolaryngology and Head and Neck Surgery,

University Hospital Maastricht, P. Debyelaan 25,

P.O Box 5800, 6202 AZ Maastricht, The Netherlands

e-mail: jstra@skno.azm.nl immunoglobulin [1]. Plasmacytomas are plasmacell tumours. They can occur solitary outside the bone marrow [solitary bone plasmacytomas (SBP), solitary extramedullary plasmacytomas (EMP)], but can also be associated with multiple myeloma (MM) [2-4]. EMPs account for 4\% of all non-epithelial tumours of the upper respiratory tract [5]. They arise submucosally (80\%), in particular at the nasopharynx, nose cavity, sinuses and tonsils.

The median age of presentation of EMP is 55 years and $75 \%$ of patients are men; $80 \%$ is localised in the head and neck region (nose, sinuses, and nasopharynx). Other localisations are the gastro-intestinal tract, lungs, mammae, testes and skin [6-9]. The most important presenting symptoms are epistaxis, rhinorrhea, sore throat, dysphonia and haemoptysis [1, 2, 8-14]. CT and/or MRI is used in monitoring the adhering lymph nodes and bone structures that can also be affected, in particular the nasal cavity and maxillary sinuses [8]. On histopathological investigation, dense plasmacells with a monotone aspect are often present. They possess a round to oval nucleus with a vesicular nuclear chromatin pattern. The nucleus is often located eccentrically in the cytoplasm (perinuclear halo) $[15,16]$. Immunohistochemistry and flow cytometry help differentiate EMP from other entities, because EMP is composed of plasmacells that also express CD138 and cytoplasmatic light chains of type $\kappa$ or $\lambda$. Negative stainings for CD20 and positive stainings for CD79 can support this diagnosis. Hotz reported 14 out of 24 patients with EMP in the head and neck region, with a monoclonal lesion after immunohistochemistry. In the other ten patients a reactive polyclonal plasmacytosis was confirmed [15].

There is an association between different monoclonal gammopathies: MM, monoclonal gammopathy of undetermined significance (MGUS), asymptomatic myeloma (SMM), indolent multiple myeloma (IMM), SBP, Waldenström 
disease, plasmacell leukaemia, amyloidosis, and heavy chain disorders [17-21]. Hussong however, recently suggested that EMP represents a form of extranodal marginal lymphoma that has undergone extensive plasmacytic differentiation [21]. In addition to the main plasmacell component, histology also shows characteristics of marginal zone lymphomas: reactive follicles, lymphoepithelial lesions, centrocyt-like cells, and monocytoid cells $[10,15]$. Wiltshaw described an association between MM and EMP 25 years ago, but also a predilection for submucosal extension, the incidence of spread to other soft tissues and the rare affection of bone marrow [22].

The treatment of EMP consists of radiotherapy and/or surgery. The prognosis after radical surgical resection is similar for radiotherapy. In non-radicality, the additional value of radiotherapy is not proven [2]. Many consider the combination of surgery and radiotherapy as treatment of choice.

The next cases describe three patients with plasmacytomas at the ears, nose and throat.

\section{Case 1}

A 62-year-old woman was referred to a tertiary reference centre with stridor. Her medical history described a MM stage IIIb, treated with autologous stemcell transplantation and chemotherapy (adriamycin, vincristine, dexamethasone) 3 years ago. Due to MM, she still used prednisone $10 \mathrm{mg}$ daily. B-symptoms, recent upper respiratory tract infection or a previous intubation were not present. Flexible laryngoscopy showed a subglottic stenosis with an estimated rest lumen of $10 \%$. A CT-scan of the neck and videofluoroscopy confirmed this stenosis (Figs. 1, 2). No abnormalities were found with laboratory investigation, in particular no anaemia, no hypercalcaemia and no renal function disorders. A protein spectrum and immunohistological staining showed a rise of monoclonal immunoglobulins, type $\kappa$.

The patient underwent an open tracheotomy and a laryngotracheoscopy with biopsy. Here, a horseshoe-shaped stenosis was observed at the subglottis with a cranial-caudal length of $1.5 \mathrm{~cm}$, a solid consistency and a free anterior border. Biopsies showed superficial atypical inflammatory cells and were not conclusive.

Thereafter, a laryngofissure was performed. Loose purple-coloured tissue was found, from which material was obtained with a curette for histopathological examination (Fig. 3). A Montgomery T-tube was placed to preserve the laryngeal lumen (Fig. 4). Immunohistochemical staining of
Fig. 1 Case 1 CT-scan neck. Sagital, coronal and axial views show a subglottic stenosis of the trachea, with a free anterior border caused by EMP
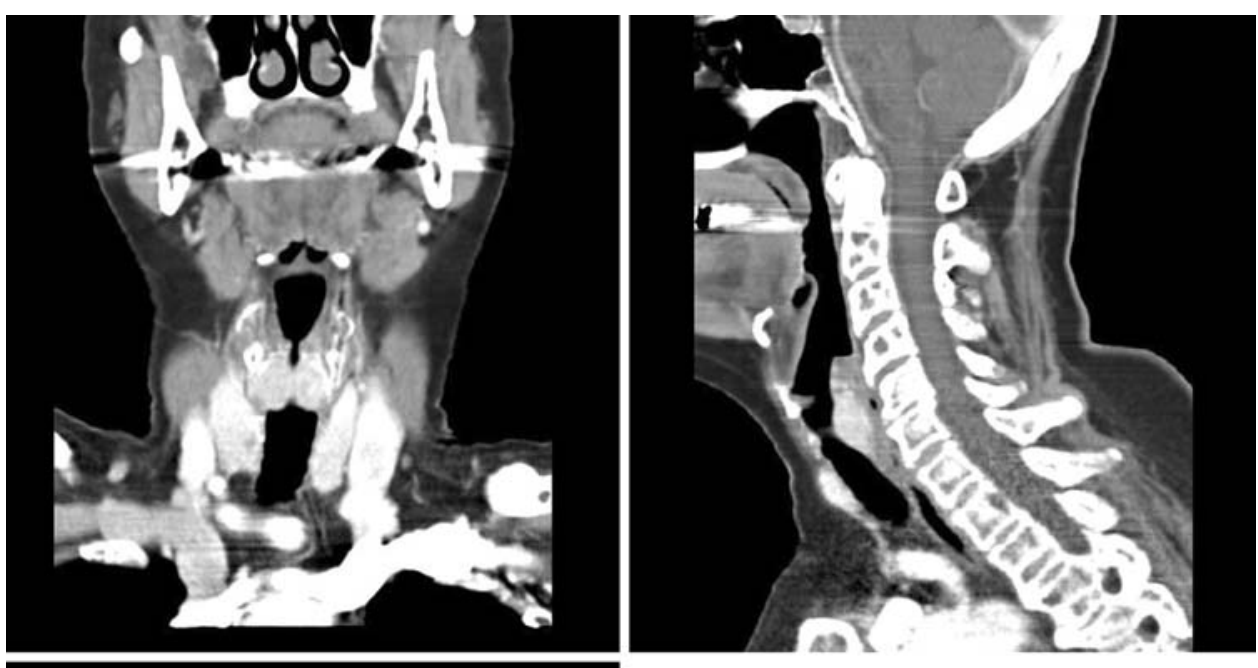

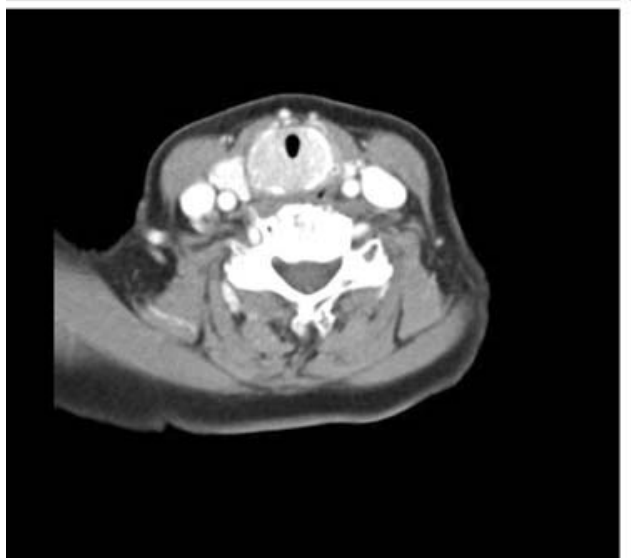




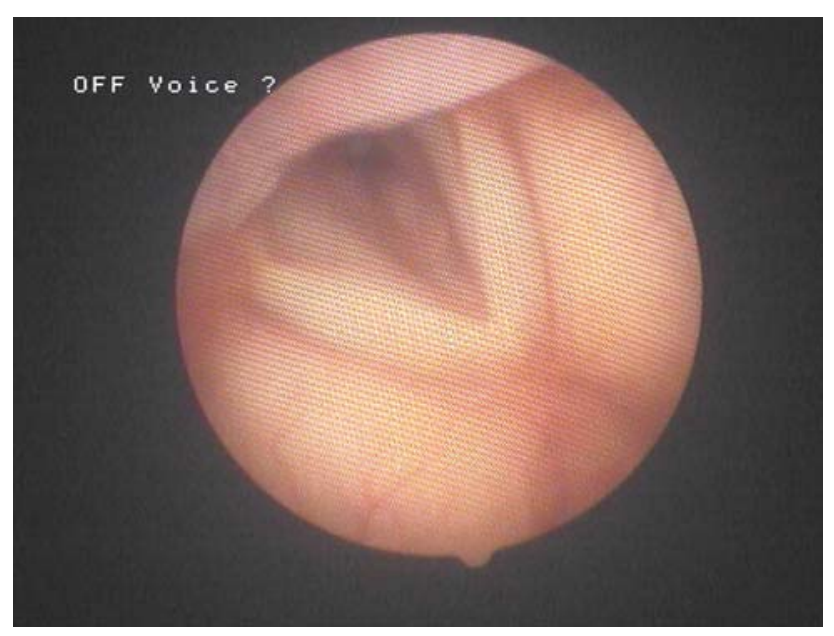

Fig. 2 Case 1 videostroboscopy subglottic stenosis caused by EMP, with free anterior border (horseshoe shaped)

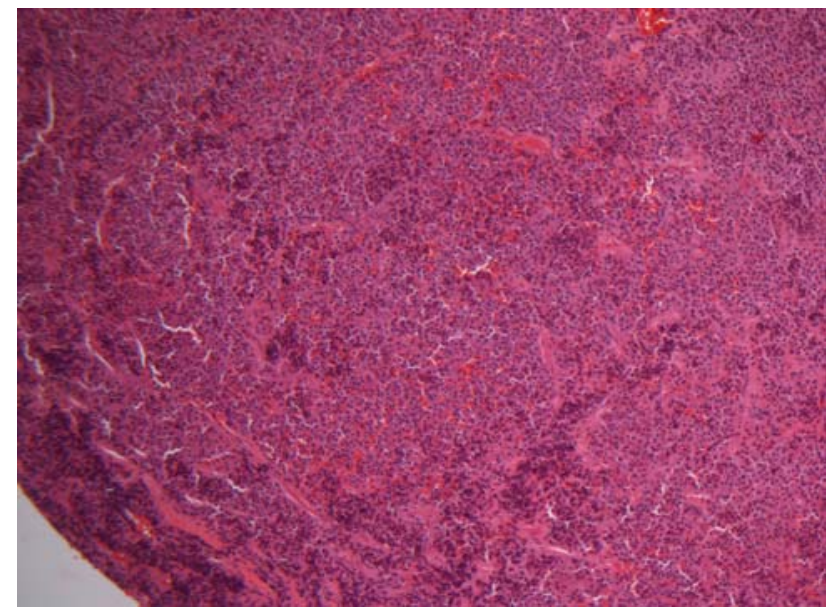

Fig. 3 Case 1 histopathology. Tissue sampling of EMP at the subglottis: dense plasmacells with a monotone aspect; round, oval nuclei with a radiated chromatin pattern, eccentric in the cytoplasm (perinuclear halo)

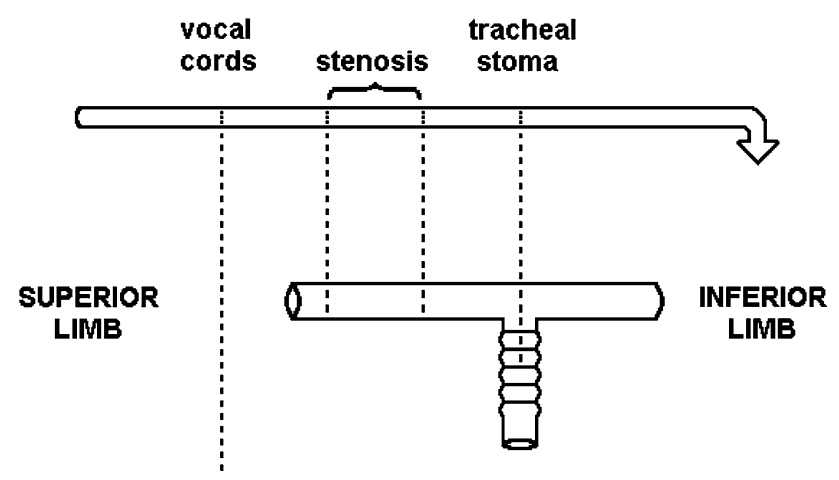

Fig. 4 Montgomery T-tube

the curetted material showed CD 138 positive cells and were conclusive for an $\operatorname{IgG} \kappa$ monoclonal plasmacytoma (Fig. 5). We diagnosed an EMP as a metastasis of MM. The patient's history was discussed in the multidisciplinary head and neck oncology meeting and she was additionally treated with chemotherapy (Thalidomide). Until now (1 year later), there is an unchanged normal value of monoclonal immunoglobulin.

\section{Case 2}

A 72-year-old man, with a medical history of insulindependent diabetes and tuberculosis, visited the referring clinic with mastoiditis on the right ear, for which antibiotic treatment was started. Four months later, he again complained of otalgia, with normal otoscopical findings. After an initial expectative management, a facial nerve-paralysis occurred. A prednisolone declining scheme (according to Taverner) and valaciclovir $500 \mathrm{mg}$ three-times daily was started.

An additional serological investigation showed no seroconversion for one of the neurotrope viruses or for Borrelia Burgdorferi. The otalgia persisted and an MRI-scan of the skull base was performed. This showed consolidation of the mastoid cells, consisting with mastoiditis and a higher signal intensity of the sinus sigmoideus. The patient was referred to our institution and underwent a posterior tympanotomy with exploration of the mastoid part of the facial nerve. The covering vessels were visible and no attempt was made for decompression. In the facial recess, tissue was found which impressed as granulation tissue. Frozen biopsy showed reactive connective tissue with a chronic plasmacellular inflammation with no signs of malignancy or malignant lymphoma.

The clinical course worsened however. The patient complained of headaches and a complete facial nerve paralysis developed (HB grade VI/VI). Simultaneously, a paresis occurred of the glossopharyngeal, the vagus and the hypoglossal nerve (Fig. 6). A CT-scan with technetium of the mastoid, showed osteolytical changes at the jugular foramen. Angiography was not suspicious for thrombosis of the sigmoid sinus. To clearly expose the jugular foramen, an infratemporal fossa approach according to Fisch type A was performed. The facial nerve was surgically decompressed, a punction of the sigmoid sinus was obtained and the jugular foramen was explored. Medial from the jugular foramen and also medial of the stylomastoid foramen, vitreous tumour tissue was found, with a different aspect than the before removed granulation tissue. Histological investigation showed a plasmacellular infiltrate, suspicious for a solitary plasmacytoma, with polyclonal immunoglobulin expression.

Additional analysis by means of lumbar punction, a skeletal survey and Bence-Jones protein in urine, were all without abnormalities. Post-operative, the headaches disappeared and 
Fig. 5 Case 1 immunohistochemical staining. a Positive staining of CD138; b positive staining for kappa light chains
Fig. 6 Case 2 the left picture shows a complete right-sided facial nerve paresis. The right picture shows a paresis of the hypoglossal nerve; the tongue is protruded
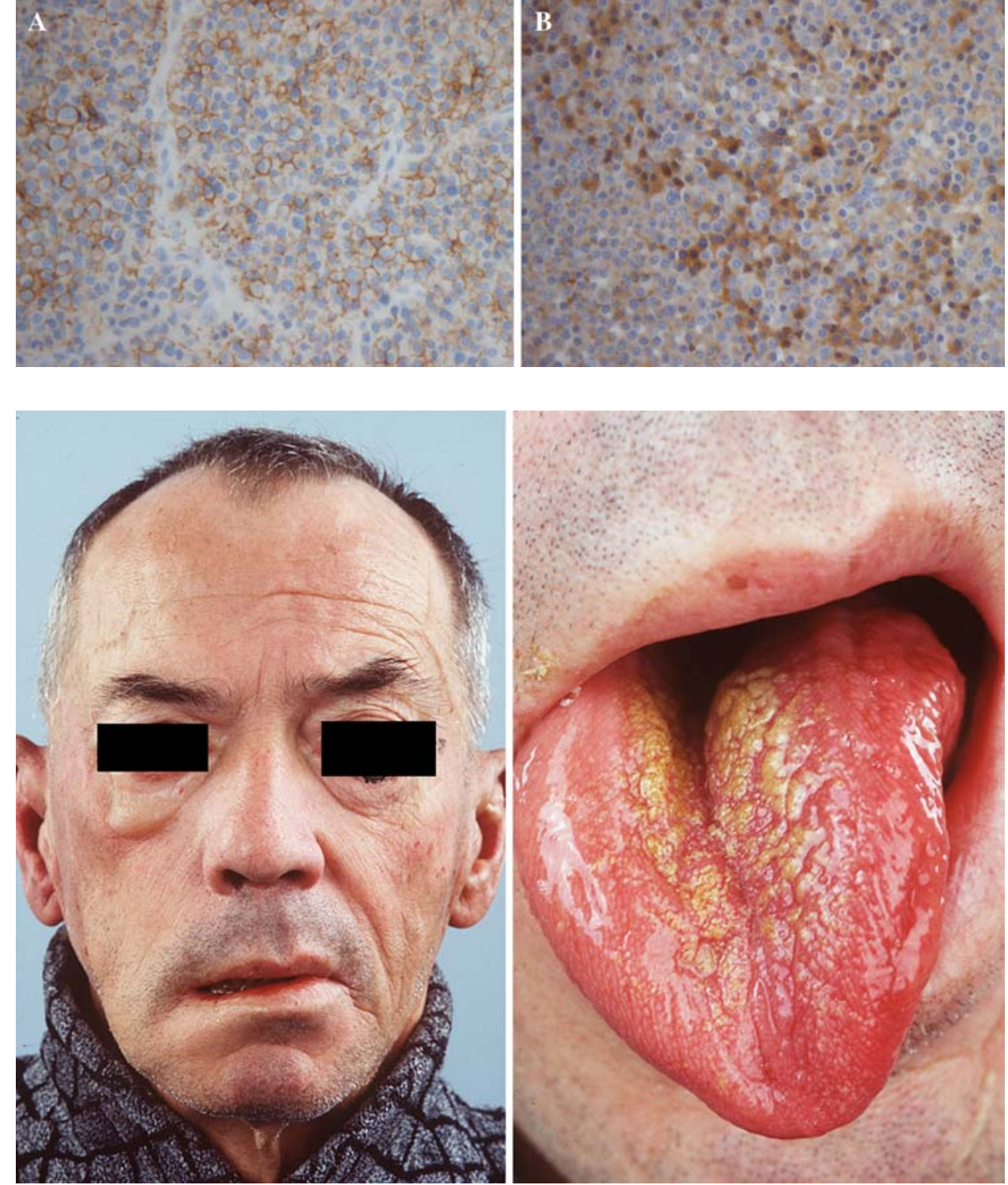

the facial nerve paresis declined to HB grade II/VI. The foramen jugular syndrome in combination with the effects of radiotherapy however, caused swallowing disorders for which a percutaneous gastrostomy was needed. A year after treatment the patient died of general discomfort.

\section{Case 3}

A 57-year-old man visited a referring clinic with a lesion of the epiglottis suspected for plasmacytoma. An excision biopsy was performed. Histological investigations supported the diagnosis: a dense proliferation of cells with round to oval, eccentric located nuclei and radiated chromatin pattern was seen. Additional immunohistochemical investigation of the tumour cells was positive for CD138 and showed monoclonality for $\lambda$ light chains.
The patient was referred to our clinic. A lesion of $5 \mathrm{~mm}$ was seen at the laryngeal side of the epiglottis. This was microlaryngoscopically excised with laser. Bronchoscopy and esophagoscopy were normal. Immunohistochemical investigations of the removed tissue, showed an inflammatory pseudo-polyp, positive for $\kappa$ and $\lambda$ light chains. It concerned a polytypical plasmacell infiltrate. This was not consistent with a suspected rest localisation of plasmacytoma. During outpatient follow-up, 2 months later, the patient complained of haemoptoea. Internal and pulmonary analysis did not show any focus of bleeding or signs of MM, nor an endobronchial lesion. Examination of head and neck did not show any abnormalities in particular at the larynx. However, a round, bowl-shaped tumour was seen at the floor of the nose. A laryngo-, pharyngoscopy and inspection of the mouth was carried out without abnormalities. A subsequent nasendoscopy showed a tumour at the 
floor of the nose just anterior to the choana, which was excised. Histopathological investigation showed a classic morphology indicating EMP.

Outpatient controls 1 month after the last intervention, showed a new lesion at the left plica ary-epiglottica. Due to the two macroscopically removed plasmacytomas and the clinical suspicion of a new third location, radiotherapy of larynx, hypopharynx and nasopharynx was started with a total dose of $50 \mathrm{~Gy}$. Haematological analysis by means of immunological, laboratory (total IgG, total IgA, total protein urine and protein spectrum), bone marrow aspiration and bone biopsy, showed no signs of MM. Two years after original presentation, this patient is still free of disease.

\section{Discussion}

Case 1 describes an EMP as recurrence of MM. MM is next to non-Hodgkin lymphoma the most occurring haematological malignancy (10\%) [23]. It accounts for $1 \%$ of all malignancy and $2 \%$ of the total malignancy-related mortality. Incidence rates are higher in men and increase in age, in particular between age 65 and 70. MM develops in the post-germinal centres of B-lymphocytes. This concerns often IgG, associated with kappa- and lambda light chains. With electrophoresis, an elevated serum paraprotein [monoclonal protein (M-protein), e.g. Beta2-microglobulin] can be shown, just as Bence-Jones protein in urine. Next to laboratory investigations, the work-up also includes radiological analysis of the axial skeletal system [17-21]. In 2003, the International Myeloma Working Group [17] published diagnostic criteria for symptomatic and asymptomatic MM, and for MGUS. EMP is characterised by an extramedullary located mass infiltrated by monoclonal plasmacells without signs of MM elsewhere in the body (Table 1). A SBP is a solitary bone lesion without signs of other bone lesions on X-ray survey and without plasmacytosis in the bone marrow.

CT or MRI with technetium contrast can differentiate between inflammatory tissue and/or tumours [24, 25]. Histological investigations by means of light microscopy of the obtained tissue offers differentiation between reactive plasmacytosis, plasmacell granulomas, bad differentiated neoplasms, immunoblastic lymphomas and mucosa-associated lymphomas (MALT) [15, 16]. Differentiation between EMP and MM is important for the prognosis. The treatment is systemic [26]. Besides serum and urine analysis, histochemical peroxidase-anti-peroxidase stainings offer help differentiating EMP and MM. Until now, an approximate 100 cases of EMP are reported in literature [26-33] of which 25 as metastasis of MM [34-37]. The diagnosis of laryngeal EMP is difficult because of the non-specific symptoms and the mucosa covering the tumour [33].

Case 2 concerns a plasmacytoma of the middle ear with extension to the jugular foramen and the temporal bone. The extension to the jugular foramen causes the so-called jugular foramen syndrome (paralysis of the cranial nerves IX, X, XI and eventually XII). The most important processes
Table 1 Criteria EMP, symptomatic multiple myeloma, asymptomatic myeloma and monoclonal gammopathy of undetermined significance $[11,17]$

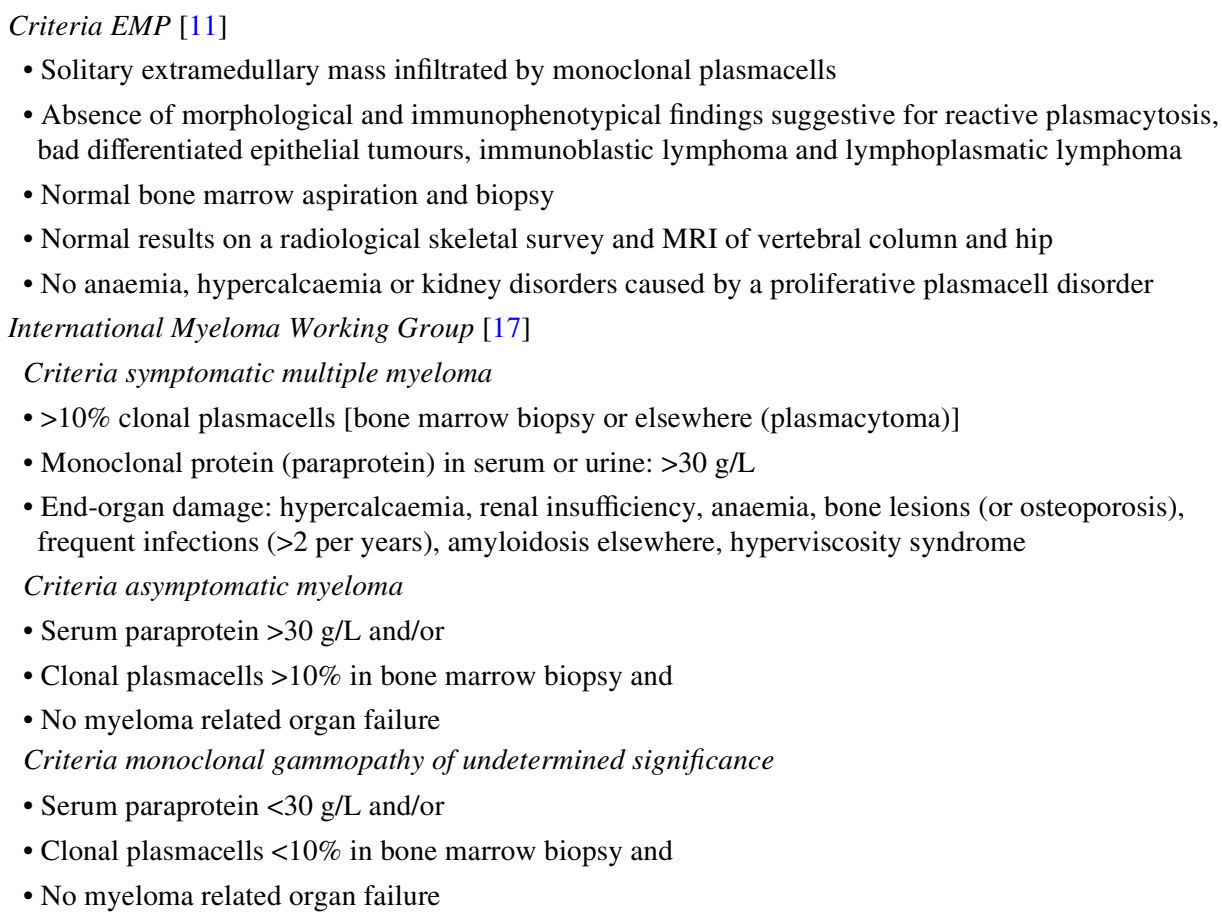


at the jugular foramen are paraganglioma, schwannoma, meningioma, periferical primitive neuro-ectodermale tumour, chondrosarcoma, chordoma, chondroblastoma, giant-cell tumour, endolymphatic sac tumour cholesterol granuloma, reactive myofibroblastic tumour, temporal bone carcinoma and finally malignant external otitis. Radiologically these processes are diagnosed by means of CT-scan (bone window), MRI and angiography before surgery [38]. Tissue sampling remains necessary. This is not always obvious due to unusual locations of EMP's.

In Case 3, EMP is recurrent. Independent of the previous location, recurrence occurs. This is important in the follow-up of EMP. About this, no guidelines are available in literature. Additional radiotherapy seems effective. In less than $5 \%$ of patients, EMP's are recurrent. There seems to be a relation between tumour size of $>5 \mathrm{~cm}$ and the recurrence rate. In nodal affection, this rate is higher. One advises to treat lymph nodes also with radiotherapy [39]. In current literature, no advantages of administration of chemotherapy before or after radiotherapy are found [9].

In approximately $30 \%$ of treated patients distant failure seem to occur. This takes place on average within 2-3 years after diagnosis [6-9]. Progression is characterised by bone lesions, bone marrow plasmacytosis and high monoclonal protein levels; $15 \%$ develops MM, some however develop multiple EMPs without intervening bone marrow plasmacytosis [10]. The most common sites for soft tissue involvement are the lymph node, skin and subcutaneous tissues [22]. Also bone lesions can occur [9]. In MM and SBP, bone involvement is usually within the axial skeleton. In contrast, in EMP, bone lesions seem to be distributed randomly throughout the skeleton [10]. Prognostic variables are hard to clarify due to the small numbers of patients in published series. Adjacent bone destruction may worsen the prognosis in EMP [13], however this difference has not always been confirmed $[8,14,40]$. There is also a trend of more frequent dissemination of EMP arising outside the head and neck region [9], for example pulmonary EMP. Most patients die of non-EMP related disorders and more than two-thirds of patients survive for more than 10 years [6-9].

\section{Conclusion}

EMP is a disorder of monoclonal immunoglobulines presenting as plasmacytomas in the head and neck region in particular. Locations are diverse, mostly affecting nose and nasopharynx, but also larynx and mastoid. Prognosis depends on the extension of the EMP and on laboratory findings. Treatment exists of radiotherapy, eventually preceeded by surgery. The prognosis is not unfavourable.
Diagnosis and differentiation of other tumours in the head and neck region is important.

Open Access This article is distributed under the terms of the Creative Commons Attribution Noncommercial License which permits any noncommercial use, distribution, and reproduction in any medium, provided the original author(s) and source are credited.

\section{References}

1. Miller FR, Lavertu P, Wanamaker JR, Bonafede J, Wood BG (1998) Plasmacytomas of the head and neck. Otolaryngol Head Neck Surg 119:614-618

2. Nofsinger YC, Mirza N, Rowan PT, Lanza D, Weinstein G (1997) Head and neck manifestations of plasma cell neoplasms. Laryngoscope 107:741-746

3. Dimopoulos MA, Hamilos G (2002) Solitry bone plasmacytoma and extramedullary plasmacytoma. Curr Treat Options Oncol 3:255-259

4. Corwin J, Lindberg RD (1979) Solitary plasmacytoma of bone vs. extramedullary plasmacytoma and their relationship to multiple myeloma. Cancer 43:1007-1013

5. Fu YS, Perzin KH (1978) Nonepithelial tumors of the nasal cavity, paranasal sinuses and nasopharynx. A clinicopathologic study. IX. Plasmacytomas. Cancer 42(5):2399-2406

6. Knowling MA, Harwood AR, Bergsagel DE (1983) Comparison of extramedullary plasmacytomas with solitary and multiple plasma cell tumors of bone. J Clin Oncol 1:255-262

7. Brinch L, Hannisdal E, Foss Abrahamsen A, Kvaloy S, Langholm R (1990) Extramedullary plasmacytomas and solitary plasma celltumours of bone. Eur J Haematol 44:131-134

8. Liebross RH, Ha CS, Cox JD, Weber D, Delasalle K, Alexanian R (1998) Solitary bone plasmacytoma: outcome and prognostic factors following radiotherapy. Int $\mathrm{J}$ Radiat Oncol Biol Phys 441:1063-1067

9. Galieni P, Cavo M, Pulsoni A, Avvisati G, Bigazzi C, Neri S et al (2000) Clinical outcome of extramedullary plasmacytoma. Haematologica $85: 47-51$

10. Alexiou C, Kau RJ, Dietzfelbinger H, Kremer M, Spiess JC, Schratzenstaller B, Arnold W (1999) Extramedullary plasmacytoma: tumor occurence and therapeutic concepts. Cancer 85:2305-2314

11. Dimopoulos MA, Kiamouris C, Moulopoulos LA (1999) Solitary plasmacytoma of bone and extramedullary plasmacytoma. Hematol Oncol Clin North Am 13:1249-1257

12. Soesan M, Paccagnella A, Chiaron-Sileni V, Salvagno L, Fornasieno A, Sotti G et al (1992) Extramedullary plasmacytoma: clinical behaviour and response to treatment. Ann Oncol 3:51-57

13. Harwood AR, Knowling MA, Bergsagel DE (1981) Radiotherapy of extramedullary plasmacytoma of the head and neck. Clin Radiol $32: 31-36$

14. Susnerwala SS, Shanks JH, Banerjee SS, Scarff JH, Farrington WT, Slevin NJ (1997) Extramedullary plasmacytoma of the head and neck region: clinicopathological correlation in 25 cases. Br J Cancer 75:921-927

15. Hotz MA, Schwaab G, Bosq J, Munck JN (1999) Extramedullary solitary plasmacytoma of the head and neck. A clinicopathological study. Ann Otol Rhinol Laryngol 108:495-500

16. Meis JM, Butler JJ, Osborne BM, Ordonez NG (1987) Solitary plasmacytoma of bone and extramedullary plasmacytomas. A clinicopathologic and immunohistochemical study. Cancer 59:1475-1485

17. International Myeloma Working Group (2003) Criteria for the classification of monoclonal gammopathies, multiple myeloma 
and related disorders: a report of the international myeloma working group. Br J Haematol 121:749-757

18. Greip PR, San Miguel J, Fonseca R, Avet-Loisau H, Jacobson JL, Rasmussen E, Crowley J, Durie BMG (2003) Development of an international prognostic index (IPI) for myelom: report of the international myeloma working group. Haematol J 4:S42

19. Durie BG, Salmon SE (1975) A clinical staging system for multiple myeloma. Correlation of measured myeloma cell mass with presenting clinical features, response to treatment and survival. Cancer 36:842-854

20. Kyle RA, Rajkumar SV (2004) Multiple myeloma. N Engl J Med 351:1860-1873

21. Hussong JW, Perkins SL, Shnitzer B, Hargreaves H, Frizzera G (1999) Extramedullary plasmacytoma. A form of marginal zone cell lymphoma. Am J Clin Pathol 111:111-116

22. Wiltshaw E (1976) The natural history of extramedullary plasmacytoma and its relation to solitary myeloma of bone and myelomatosis. Medicine 55:217-238

23. Rajkumar SV (2005) Novel approaches to the management of myeloma. Oncolgy 19:621-625

24. Dimopoulos MA, Moulopoulos LA, Maniatis A, Alexanian R (2000) Solitary plasmacytoma of bone and asymptomatic multiple myeloma. Blood 96:2037-2044

25. Moulopoulos LA, Dimopoulos MA, Weber D, Fuller L, Libhitz H, Alexanian R (1993) Magnetic resonance imaging in the staging of solitary plasmacytoma of bone. J Clin Oncol 11:1311-1315

26. Werner JA, Lippert BM, Schmidt D, Rudert H (1991) Subglottic metastasis of multiple myeloma. Case report and review of the literature of laryngeal plasmacytoma. HNO 39:405-409

27. Horny HP (1994) The larynx in lymphoproliferative and myeloproliferative diseases. I: an overview with special reference to primary laryngeal malignant lymphomas and plasmacytomas. HNO 42:334-339

28. Sakiyama S, Kondo K, Mitsuteru Y, Takizawa H, Kenzaki K, Miyoshi T, Abe M, Wakatsuki S, Monden Y (2005) Extramedullary plasmacytoma immunoglobulin D (lambda) in the chest wall and the subglottic region. J Thorac Cardiovasc Surg 129:1168-1169
29. O'Neal ML, Entel RJ (2002) Plasmacytoma of the cricoid cartilage with airway mass effect. ORL J Otorhinolaryngol Relat Spec 64:373-376

30. Wein RO, Topf P, Sham RL (2002) Subglottic plasmacytoma: a case report and review of the literature. Am J Otolaryngol 23:112-118

31. Maheshwari GK, Baboo HA, Gopal U, Shah NM (2001) Extramedullary plasmacytoma of the larynx: a case report. J Indian Med Assoc 99:267-268

32. Rodriguez-de-Velasquez A, Weber AL, Montgomery W (1996) Extramedullary laryngeal plasmacytoma. Ann Otol Rhinol Laryngol 105:483-486

33. Rabinov RC, Castro DJ, Calcaterra TC, Fu YS, Anderson CT, Bates E, Soudant J, Saxton R (1993) Subglottic plasmacytoma: the use of jet ventilation and contact Nd:YAG laser for tissue diagnosis. J Clin Laser Med Surg 11:131-134

34. Peretti G, Piazza C, Provenzano L, Giudice M (2005) Multiple myeloma involving the cricoid cartilage. Otolaryngol Head Neck Surg 133:643

35. Sinclair D, Resouly A, Spedding A (2003) Stridor: unusual presentation of multiple myeloma. J Laryngol Otol 117:829-831

36. Yoskovitch A, al-Abdulhadi K, Wright ED, Watters AK, Chagnon F (1998) Myeloma involving the cricoid cartilage. J Otolaryngol 27:168-170

37. Rutka J, Noyek AM, Chapnik JS, Amato D, Couter N, Steinhardt MI (1985) Multiple myeloma involving the cricoid cartilage. J Otolaryngol 14:309-312

38. Löwenheim H, Koerbel A, Ebner FH, Kumagami H, Ernemann U, Tatagiba M (2006) Differentiating imaging in primary and secondary tumors of the jugular foramen. Neurosurg Rev 29:1-11

39. Tsang RW, Gospodarowicz MK, Pintilie M, Bezjak A, Wells W, Hodgson DC et al (2001) Solitary plasmacytoma treated with radiotherapy: impact of tumor size on outcome. Int J Radiat Oncol Biol Phys 50:113-120

40. Mayr N, Wen BC, Hussey DH, Burns CP, Staples JJ, Vigliotti AP (1990) The role of radiation therapy in the treatment of solitary plasmacytomas. Radiother Oncol 17:293-303 